Article

\title{
Correlation for Condensation Heat Transfer in a 4.0 mm Smooth Tube and Relationship with R1234ze(E), R404A, and R290
}

\author{
Norihiro Inoue ${ }^{1, *}$, Masataka Hirose ${ }^{2}$, Daisuke Jige ${ }^{1}$ and Junya Ichinose ${ }^{3}$ \\ 1 Department of Marine Electronics and Mechanical Engineering, Tokyo University of Marine Science and \\ Technology, Tokyo 135-8533, Japan; djige00@kaiyodai.ac.jp \\ 2 Graduate School of Marine Science and Technology, Tokyo University of Marine Science and Technology, \\ Tokyo 135-8533, Japan; hirose-m@toba-cmt.ac.jp \\ 3 Department of Ocean Mechanical Engineering, National Fisheries University, \\ Shimonoseki-city 759-6595, Japan; ichinose@fish-u.ac.jp \\ * Correspondence: inoue@kaiyodai.ac.jp; Tel.: +81-3-5245-7479
}

Received: 18 October 2018; Accepted: 14 November 2018; Published: 16 November 2018

\begin{abstract}
In this study, the condensation heat transfer coefficient and pressure drop characteristics of a $4 \mathrm{~mm}$ outside diameter smooth tube, using R32, R152a, R410A, and R1234ze(E) refrigerants, were examined. Condensation heat transfer coefficients and pressure drops were measured at a saturation temperature of $35^{\circ} \mathrm{C}$, in the region of mass velocities from 100 to $400 \mathrm{~kg} \mathrm{~m}^{-2} \mathrm{~s}^{-1}$. The frictional pressure drop, and the condensation heat transfer from the new measurements, using R1234ze(E) as a refrigerant, were compared with those of R32, R152a, and R410A, in the smooth tube. Experimental values of condensation heat transfer coefficient of smooth tube were also compared to the predicted values obtained using the previously established correlations. The previous correlation from Cavallini et al., for the condensation heat transfer coefficient of small-diameter smooth tube, was estimated to be within $\pm 30 \%$. However, the general correlation, which can be easily predicted, for condensation heat transfer inside small-diameter smooth tubes, was suggested, and the relationship of the general correlation was compared with data for R1234ze(E) obtained by us, and R404A and R290 obtained by other researchers.
\end{abstract}

Keywords: condensation heat transfer; pressure drop; small-diameter; smooth tube; R1234ze(E); correlation

\section{Introduction}

Aggravated global warming has become a concern as the energy demands of emerging countries are increasing. Moreover, continuously increasing demand for air-conditioning and hot-water supply are to be expected, due to improved life standard. Therefore, enhanced energy saving of air-conditioning and hot-water supply systems is required. For these reasons, in the refrigeration and air-conditioning field, tubes with $5 \mathrm{~mm}$ outside diameter or smaller have been developed in Japan and elsewhere, and that has simultaneously attracted a lot of attention in environment-responsive technology, by reducing the net amount of the refrigerant through downsizing the heat exchanger. It is necessary to predict the condensation heat transfer and pressure drop characteristics in a small-diameter smooth tube for optimum thermal design of the heat exchangers.

Many studies have been conducted about condensation characteristics using conventionaldiameter smooth tubes with over $6.35 \mathrm{~mm}$ outer diameter [1-6]. Son et al. [7] carried out experiments of horizontal small-diameter smooth tubes for condensation of R22, R134a, and R410A, and then a new condensation heat transfer correlation was proposed. Matsumoto et al. [8] conducted experiments 
on the condensation heat transfer in a horizontal single rectangular mini-channel with a hydraulic diameter of about $1 \mathrm{~mm}$. Longo et al. [9,10] investigated the condensation heat transfer of R134a, R1234yf, R1234ze(E), R32, and R410A in a 4 mm outside diameter horizontal smooth tube.

Inoue and Ichinose [11] have proposed the general correlation of friction factor for single-phase flow, based on the experimental pressure drop of single-phase flow, using $4 \mathrm{~mm}$ outside diameter smooth and 10 kinds of microfin tubes. Furthermore, Ichinose and Inoue [12] have proposed general correlations of friction factor for two-phase flow, while condensation heat transfer can be estimated using the friction factor for single-phase flow. However, these correlations of smooth and microfin tubes were based on experimental results of R410A and in a large mass velocity condition, from 320 to $1180 \mathrm{~kg} \mathrm{~m}^{-2} \mathrm{~s}^{-1}$. The low flow rate operation of the refrigerant, against the increase of the frictional pressure drop, is required by multi-pass flow channel. For a low mass velocity condition, Hirose et al. [13] have proposed general correlations of friction factor for two-phase flow, and condensation heat transfer in microfin tubes can be estimated using 3 kinds of refrigerants (R32, R410A, R152a), 4 mm outside diameter smooth and 10 kinds of microfin tubes. Therefore, there is a need to investigate heat transfer characteristics and accumulated experimental data in a low mass velocity condition.

In this paper, the condensation heat transfer coefficient and pressure drop for R32, R410A, R152a, and R1234ze(E) refrigerators, in a $4 \mathrm{~mm}$ outside diameter tube, at a low mass velocity condition from ca. 100 to $400 \mathrm{~kg} \mathrm{~m}^{-2} \mathrm{~s}^{-1}$, were determined. The general correlation for condensation heat transfer inside small-diameter smooth tubes was suggested, based on the obtained R32, R410A, and R152a values, and the same with the method of microfin tubes case [13], which were compared with the results for R1234ze(E) and data for R404A and R290 from other researchers.

\section{Experimental Setup and Procedure}

A schematic of the experimental setup is shown in Figure 1, a vapor compression heat pump system consisting of a refrigerant loop and four heat-source water loops. The refrigerant loop consists of a compressor, oil separator, pre-condenser, test section, rear condenser, liquid receiver, mass flow meter, expansion valve, and evaporator. Each heat-source water loop consists of a water tank, temperature control unit, water pump, and flow meters. The refrigerant flow rate is adjusted by the expansion valve, bypass valve, and rotational speed of the compressor.

Details of the pre-condenser and test section are shown in Figure 2 for measurements using R1234ze(E), which is a double-tube heat exchanger consisting of three subsections with a length of $200 \mathrm{~mm}$. In each subsection, a test tube is cooled by water passing through the annulus, while the refrigerant flows within the inner tube. Measurement lengths for the pressure drop and heat transfer are $800 \mathrm{~mm}$ and $200 \mathrm{~mm}$, respectively. Therefore, the test section for the measurements using R32, R410A, and R152a, was different from that of R1234ze(E), and it was shown in a published paper [13]. The device measurement accuracies were shown in Table 1, and the reliability of the experimental loop confirmed that heat balance is consistent, with a $10 \%$ difference between the refrigerant and heat-source water side.

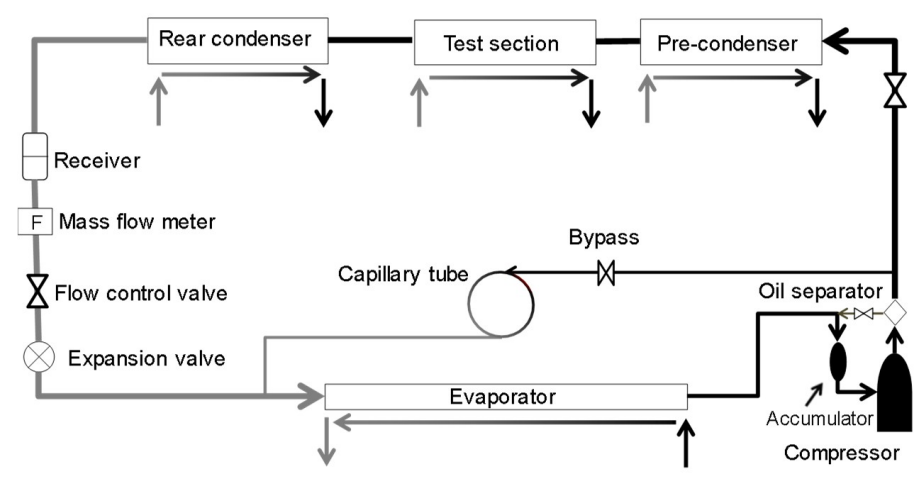

Figure 1. Schematic of the experimental setup. 


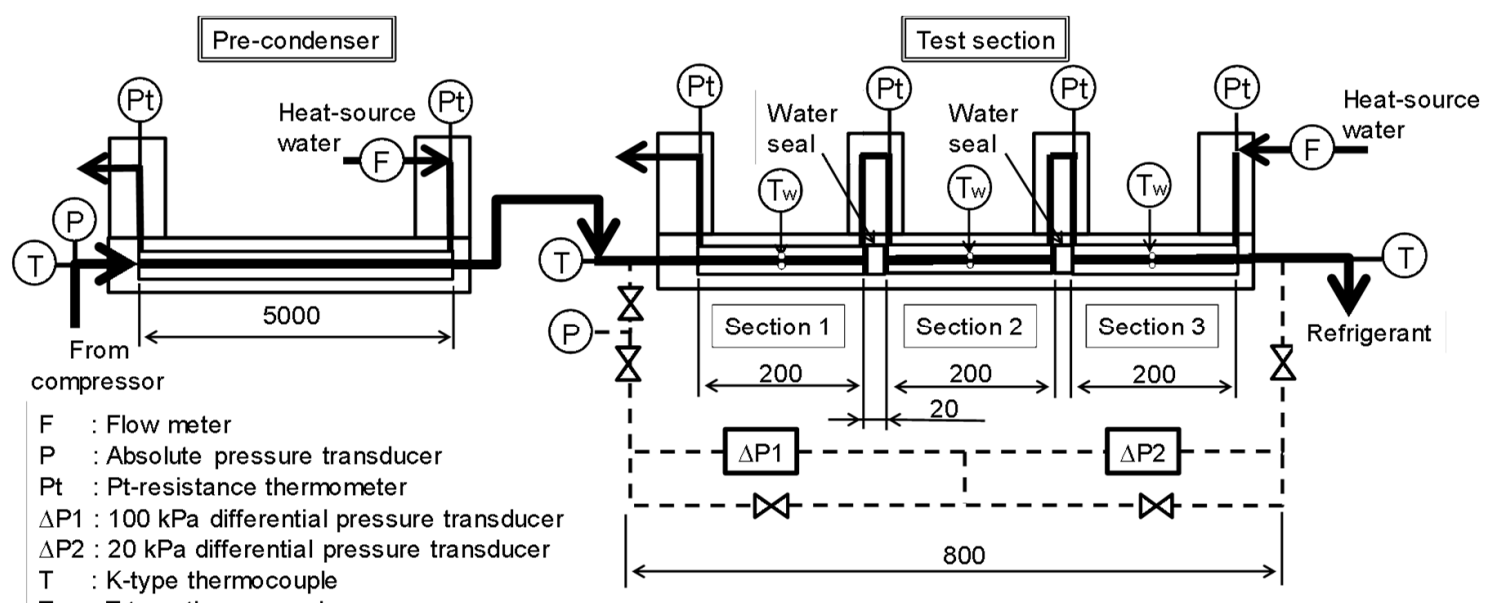

Figure 2. Details of the pre-condenser and test section.

Table 1. Measurement accuracies of the measuring devices.

\begin{tabular}{ccc}
\hline Instrument & Full Scale & Uncertainty \\
\hline T-type thermocouple & - & $0.05 \mathrm{~K}$ \\
Coriolis mass flow meter & $43 \mathrm{~kg} \mathrm{~h}^{-1}$ & $0.2 \%$ \\
Absolute pressure transducer & $3 \mathrm{MPa}$ & $\pm 0.3 \mathrm{kPa}$ \\
Differential pressure transducer & $100 \mathrm{kPa}$ & $\pm 0.2 \mathrm{kPa}$ \\
Differential pressure transduscer & $20 \mathrm{kPa}$ & $\pm 0.04 \mathrm{kPa}$ \\
Pt-resistance thermometer & - & $\pm 0.04 \mathrm{~K}$ \\
Volumetric flow meter & $500 \mathrm{~L} \mathrm{~h}^{-1}$ & $\pm 0.01 \mathrm{~L} \mathrm{~h}^{-1}$ \\
\hline
\end{tabular}

The test copper tube used a smooth tube, with an outer diameter of $4.02 \mathrm{~mm}$ and an inner diameter of $3.48 \mathrm{~mm}$. In the experimental setup, the pressure and the thermal equilibrium vapor quality of inlet No.1 subsection are changed to steady values by the pre-condenser, and the condensation process of refrigerant progresses from the No.1 to the No.3 subsection.

Under experimental conditions, the refrigerant mass velocity varied from 100 to $400 \mathrm{~kg} \mathrm{~m}^{-2} \mathrm{~s}^{-1}$, and the saturation temperature at the inlet test section was maintained at $35{ }^{\circ} \mathrm{C}$. The amount of quality change, which depended on the refrigerant, mass velocity, and heat flux, in each subsection, was approximately 0.2 on average, with a maximum of 0.35 for R410A in mass velocity of $100 \mathrm{~kg} \mathrm{~m}^{-2} \mathrm{~s}^{-1}$. The physical properties of used refrigerants in this study are shown in Table 2.

Table 2. Physical properties of used refrigerants at saturation state temperature $35^{\circ} \mathrm{C}$.

\begin{tabular}{|c|c|c|c|c|c|c|}
\hline & R410A & $\mathbf{R} 32$ & R152a & R1234ze(E) & R404A & $\mathbf{R} 290$ \\
\hline Global Warming Potential* & 1924 & 677 & 138 & $<1$ & 3942 & 3 \\
\hline Pressure (MPa) & 2.14 & 2.19 & 0.79 & 0.67 & 1.61 & 1.22 \\
\hline Dew point temp. $\left({ }^{\circ} \mathrm{C}\right)$ & 35.0 & & & & 35.0 & \\
\hline Boiling point temp. $\left({ }^{\circ} \mathrm{C}\right)$ & 34.9 & 35.0 & 35.0 & 35.0 & 34.6 & 35 \\
\hline Vapor density $\left(\mathrm{kg} \mathrm{m}^{-3}\right)$ & 88.9 & 63.3 & 24.6 & 35.3 & 87.5 & 26.6 \\
\hline Liquid density $\left(\mathrm{kg} \mathrm{m}^{-3}\right)$ & 1005 & 917.1 & 873.4 & 1129 & 995.0 & 476.1 \\
\hline Vapor viscosity ( $\mu \mathrm{Pa} \mathrm{s})$ & 14.5 & 13.5 & 10.5 & 12.7 & 12.5 & 8.7 \\
\hline Liquid viscosity $(\mu \mathrm{Pa} s)$ & 103.2 & 101.0 & 145.3 & 177.2 & 119.4 & 87.4 \\
\hline Vapor thermal cond. $\left(\mathrm{mW} \mathrm{m}^{-1} \mathrm{~K}^{-1}\right)$ & 17.7 & 17.2 & 16.1 & 14.5 & 17.7 & 20.5 \\
\hline Liquid thermal cond. $\left(\mathrm{mW} \mathrm{m}{ }^{-1} \mathrm{~K}^{-1}\right)$ & 83.6 & 118.3 & 93.8 & 70.9 & 60.0 & 89.1 \\
\hline Latent heat $\left(\mathrm{kJ} \mathrm{kg}^{-1}\right)$ & 169 & 249 & 267 & 159 & 128 & 317 \\
\hline
\end{tabular}




\section{Method of Experimental Data Analysis}

In each subsection, the frictional pressure drop during the condensation process $\Delta P_{\mathrm{F}}$ is defined as follows:

$$
\Delta P_{\mathrm{F}}=\Delta P-\Delta P_{\mathrm{M}},
$$

where $\Delta P$ is the measured pressure drop of the refrigerant through each subsection, and $\Delta P_{\mathrm{M}}$ is the acceleration pressure drop. The acceleration pressure drop, $\Delta P_{\mathrm{M}}$, is calculated by Equation (2).

$$
\Delta P_{\mathrm{M}}=\Delta\left\{\frac{G^{2} x^{2}}{\xi \rho_{\mathrm{V}}}+\frac{G^{2}(1-x)^{2}}{(1-\xi) \rho_{\mathrm{L}}}\right\}
$$

In Equation (2), $\xi$ is a void fraction, $G$ is the refrigerant mass velocity, and $x$ is the vapor quality. The thermodynamic and transport properties of the refrigerants and heat-source water were found from REFPROP Ver. 9.1 [14]. The void fraction $\xi$ could be used from the below Equation (3), as proposed by Smith [15] in the smooth tube.

$$
\xi=\left[1+\frac{\rho_{\mathrm{V}}}{\rho_{\mathrm{L}}}\left(\frac{1-x}{x}\right)\left(0.4+0.6 \sqrt{\frac{\frac{\rho_{\mathrm{L}}}{\rho_{\mathrm{V}}}+0.4 \frac{1-x}{x}}{1+0.4 \frac{1-x}{x}}}\right)\right]^{-1}
$$

The local thermal equilibrium quality for each subsection $x_{\mathrm{n}}$ is defined as follows:

$$
x_{\mathrm{n}}=\frac{h_{n}-h_{\mathrm{L} n}}{h_{\mathrm{Vn}}-h_{\mathrm{Ln}}}
$$

where $h_{\mathrm{Vn}}$ and $h_{\mathrm{Ln}}$ are the enthalpies of liquid and vapor in the saturation state, and $h_{\mathrm{n}}$ is the local enthalpy of each subsection. $h_{\mathrm{Vn}}$ and $h_{\mathrm{Ln}}$ are found by the saturated pressure of each subsection. The local enthalpy of No. 1 subsection center is determined as follows:

$$
h_{1}=h_{\text {pre }}-\frac{Q_{\text {cpre }}}{m_{\mathrm{r}}}-\frac{Q_{\mathrm{c} 1}}{m_{\mathrm{r}}} \times \frac{1}{2},
$$

where $h_{\text {pre }}$ is the enthalpy of the superheated vapor at the inlet of the pre-condenser, and $Q_{\text {pre }}$ and $Q_{\mathrm{c} 1}$ are the heat transfer rates in the pre-condenser and No. 1 subsection, respectively. $m_{\mathrm{r}}$ is the refrigerant flow rate; $h_{\text {pre }}$ is found by the measured pressure and temperature at the inlet mixing chamber of pre-condenser, while the local enthalpy of the No. $\mathrm{n}$ subsection center, after the second subsection, is found as follows:

$$
h_{\mathrm{n}}=h_{\mathrm{n}-1}-\frac{Q_{\mathrm{cn}}}{m_{\mathrm{r}}} \times \frac{1}{2} .
$$

The condensation heat transfer coefficient $\alpha$ is defined as

$$
\alpha=Q_{\mathrm{c}} /\left\{\pi d_{\mathrm{i}} L\left(T_{\mathrm{r}}-T_{\mathrm{wi}}\right)\right\},
$$

where $Q_{\mathrm{c}}$ is the heat transfer rate in each subsection, obtained from the heat balance of the heat-source water flowing inside the annulus; $L$ is the effective heat transfer length, and $d_{\mathrm{i}}$ is the inner diameter of the tube. $T_{\text {wi }}$ is the arithmetic mean temperature of the tube's inner wall surface. $T_{\mathrm{r}}$ was found by the measured refrigerant pressure, and $T_{\mathrm{wi}}$ was calculated from the measured temperature of the tube's outside wall surface from a one-dimensional thermal conductivity equation.

$$
T_{\mathrm{wi}}=T_{\mathrm{wo}}+Q_{\mathrm{c}} \ln \left(d_{\mathrm{o}} / d_{\mathrm{i}}\right) /\left(2 \pi \lambda_{\mathrm{w}} L\right),
$$

where $d_{\mathrm{o}}$ is the outside diameter of the tube, and $\lambda_{\mathrm{w}}$ is the thermal conductivity of the tube. 


\section{Results and Discussion}

\subsection{Pressure Drop in a Smooth Tube}

Figure 3 shows the relationship for R1234ze(E) between the frictional pressure drop $\Delta P_{\mathrm{F}} / \Delta \mathrm{Z}$ and the wetness $1-x$ for the mass velocities of 400, 200, and $100 \mathrm{~kg} \mathrm{~m}^{-2} \mathrm{~s}^{-1}$. As shown in the figure, the frictional pressure drop decreases as mass velocity decreases, and it decreases as vapor velocity and wall shear stress decrease, as condensation proceeds. The comparison of results for different refrigerants shows that the frictional pressure drop of R410A is lower than that of other refrigerants, under most conditions. The second lowest is that of R32, and the highest is that of R152a. The frictional pressure drop of R1234ze(E) was shown to be lower than that of R152a, and higher than that of R32.

Figure 4 shows the present data of $\mathrm{R} 1234 \mathrm{ze}(\mathrm{E})$ as the relationship between $\Phi_{\mathrm{V}}$ and $X_{\mathrm{tt}}$. The experimental results of R1234ze(E) can be correlated to approximately $\pm 30 \%$ by Equation (11), proposed by Hirose et al. [12], with a two-phase pressure drop multiplier $\Phi_{\mathrm{V}}$ based on the obtained R32, R410A, and R152a of smooth and microfin tubes.

$$
\Phi_{\mathrm{V}}=1+1.55 X_{\mathrm{tt}}^{0.4}
$$

where the Lockhart-Martinelli parameter, $X_{\mathrm{tt}}$, and the two-phase pressure drop multiplier, $\Phi_{\mathrm{V}}$, are respectively defined as

$$
\begin{gathered}
X_{\mathrm{tt}}=\{(1-x) / x\}^{0.9}\left(\rho_{\mathrm{V}} / \rho_{\mathrm{L}}\right)^{0.5}\left(\mu_{\mathrm{L}} / \mu_{\mathrm{V}}\right)^{0.1}, \\
\Phi_{\mathrm{V}}=\sqrt{\left(\Delta P_{\mathrm{F}} / \Delta Z\right) /\left(\Delta P_{\mathrm{V}} / \Delta Z\right)},
\end{gathered}
$$

where $\Delta P_{\mathrm{F}} / \Delta \mathrm{Z}$ is the frictional pressure drop of the vapor/liquid two-phase flow, $\left(\Delta P_{\mathrm{V}} / \Delta \mathrm{Z}\right)$ is the frictional pressure drop when the vapor component flows alone inside a tube, and can be found by the following equation:

$$
\left(\Delta P_{\mathrm{V}} / \Delta Z\right)=2 f_{\mathrm{V}} G^{2} x^{2} /\left(\rho_{\mathrm{V}} d_{\mathrm{i}}\right)
$$

where the friction factors $f_{V}$ were provided by Inoue and Ichinose [11], for a single-phase flow inside a $4 \mathrm{~mm}$ outside smooth tube, as follows:

$$
f_{\mathrm{V}}=0.26 \operatorname{Re}_{\mathrm{V}}^{-0.38}
$$

where $R e_{\mathrm{V}}$ is the vapor Reynolds number of the refrigerant, and is defined as follows:

$$
R e_{\mathrm{V}}=G x d_{\mathrm{i}} / \mu_{\mathrm{V}}
$$

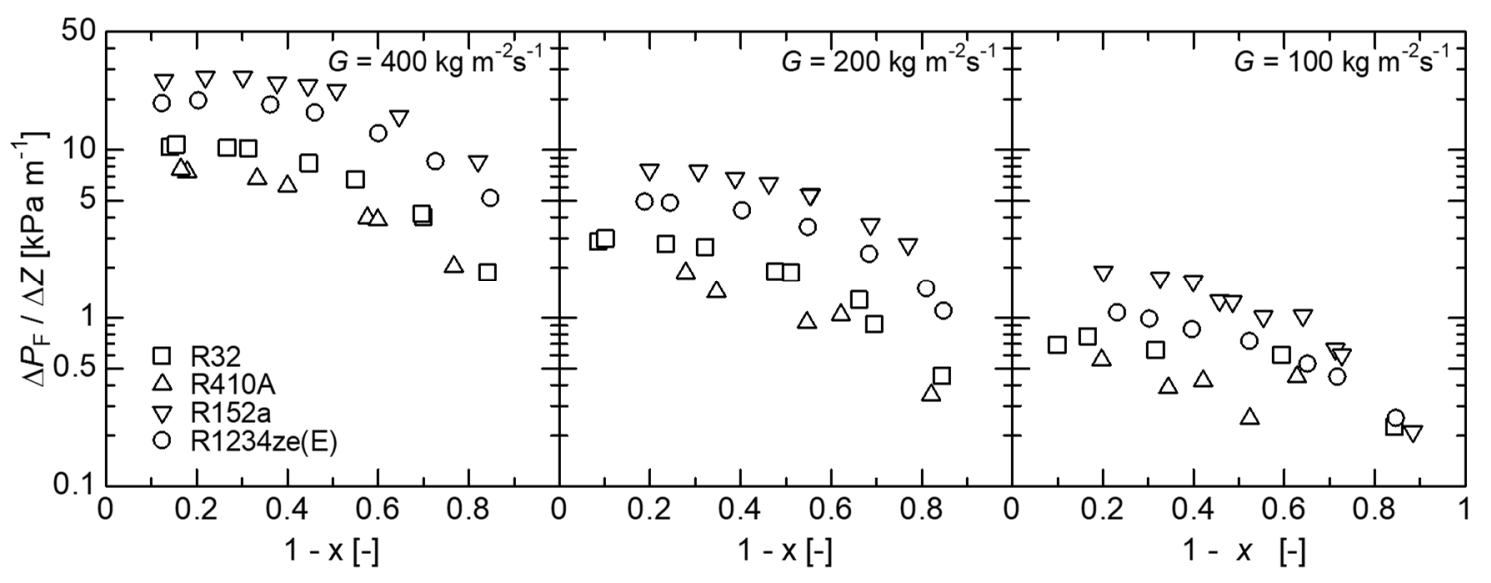

Figure 3. Relationship between pressure drop and wetness for the small-diameter smooth tube. 


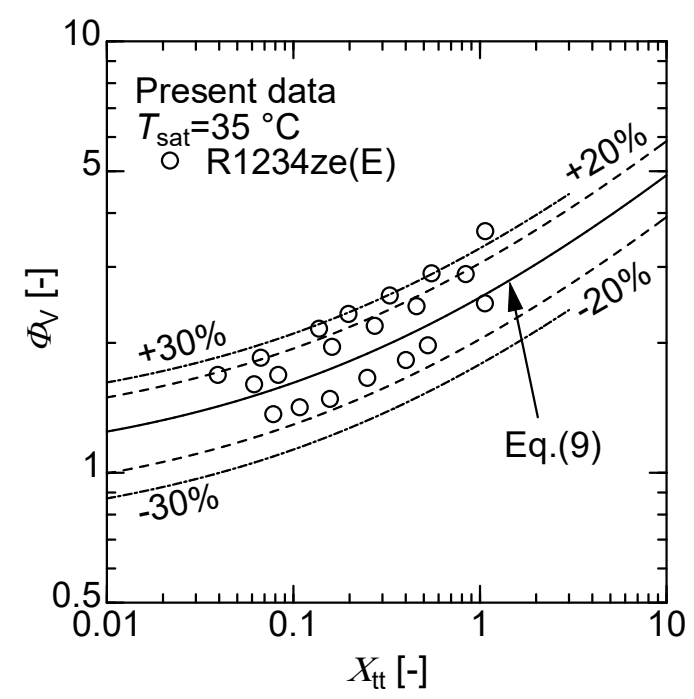

Figure 4. Comparison of pressure drop between that predicted by Hirose et al. correlation and R1234ze(E).

\subsection{Condensation Heat Transfer Coefficient}

Figure 5 shows the relationship of R1234ze(E) between the condensation heat transfer coefficient $\alpha$, and the wetness $1-x$ at the mass velocities of 400,200 , and $100 \mathrm{~kg} \mathrm{~m}^{-2} \mathrm{~s}^{-1}$. From the results, the heat transfer coefficient of R1234ze(E) is lower than that of R152a, as well as that of R32, R410A, and R152a. The heat transfer coefficient decreased as wetness increased, because the heat transfer resistance of the liquid film increased as condensation proceeded. Additionally, the forced convection condensation decreased as the refrigerant vapor velocity decreased. A comparison of the results for different refrigerants shows that the heat transfer coefficient of R152a is higher than those of other refrigerants, under most conditions. Moreover, the heat transfer coefficient of R1234ze(E) is lower than that of R152a, as well as that of R32, R410A, and R152a.

Figure $6 \mathrm{a}-\mathrm{d}$ show the comparison of experimental values, including R1234ze(E), to values estimated from previous correlations, Haraguchi et al. [2], Dobson and Chato [3], Cavallini et al. [4] and Son and Lee [7], respectively. The Haraguchi et al. correlation, shown in Figure 6a, overestimates the experimental values by up to $80 \%$. However, the predicted trends agree with the measured values. The Dobson and Chato correlation, shown in Figure 6b, overestimates the experimental values by up to $80 \%$. However, the predicted trends agree with the measured values. Figure $6 \mathrm{c}$ shows that the experimental values and the values predicted by the Cavallini et al. correlation can be correlated within $\pm 30 \%$. Figure $6 \mathrm{~d}$ shows that the Son and Lee correlation overestimates the experimental values by up to $150 \%$.

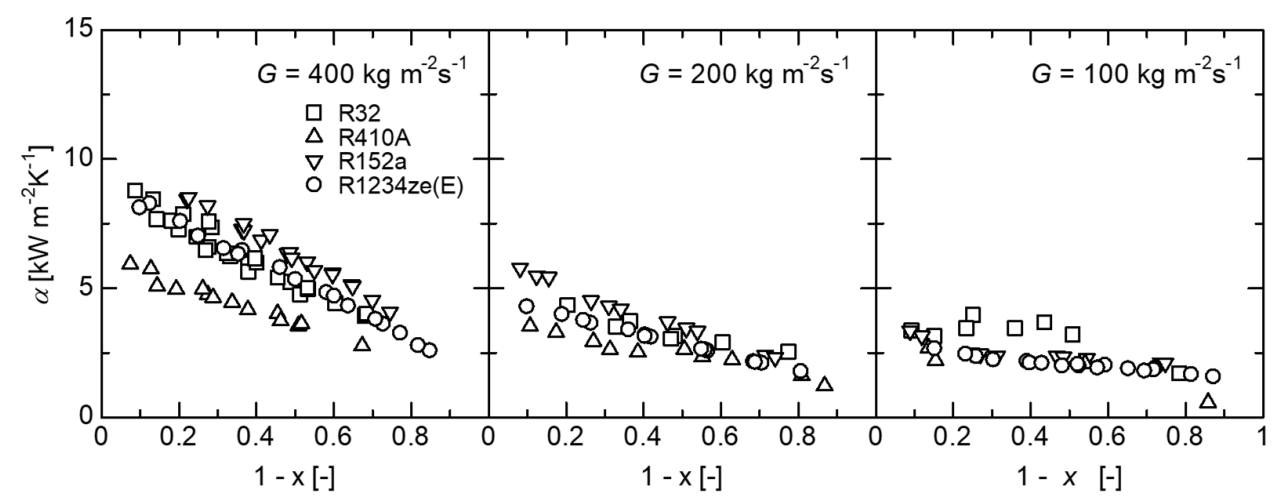

Figure 5. Relationship between condensation heat transfer and wetness for the small-diameter smooth tube. 


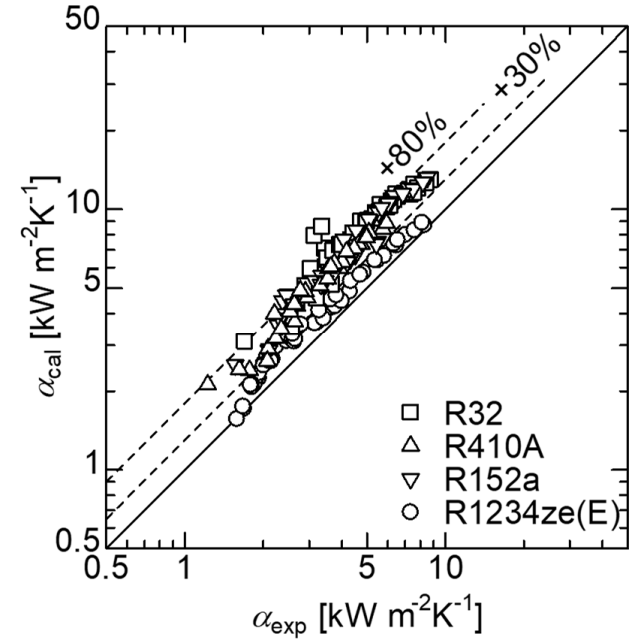

(a) Haraguchi et al.(1994)

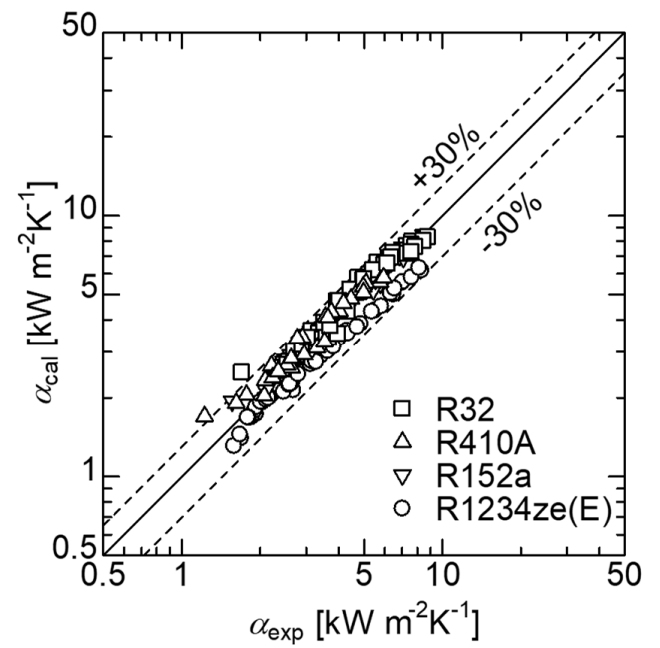

(c) Cavallini et al. (2006)

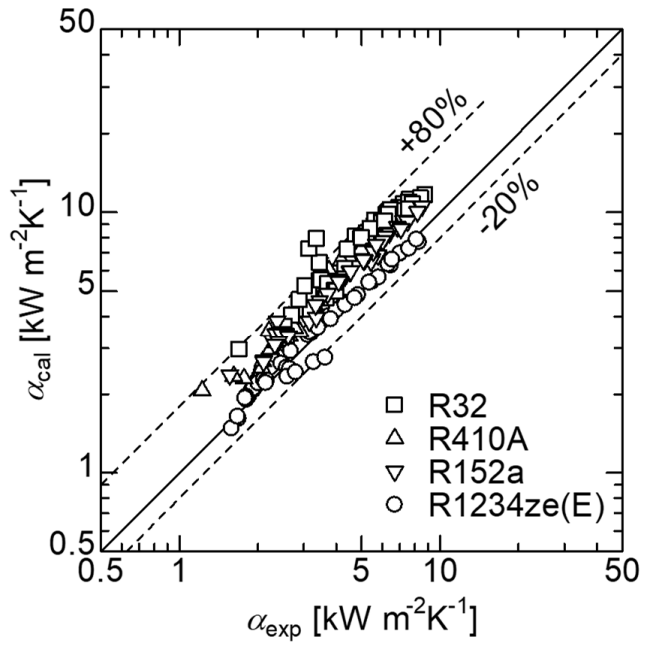

(b) Dobson and Chato(1998)

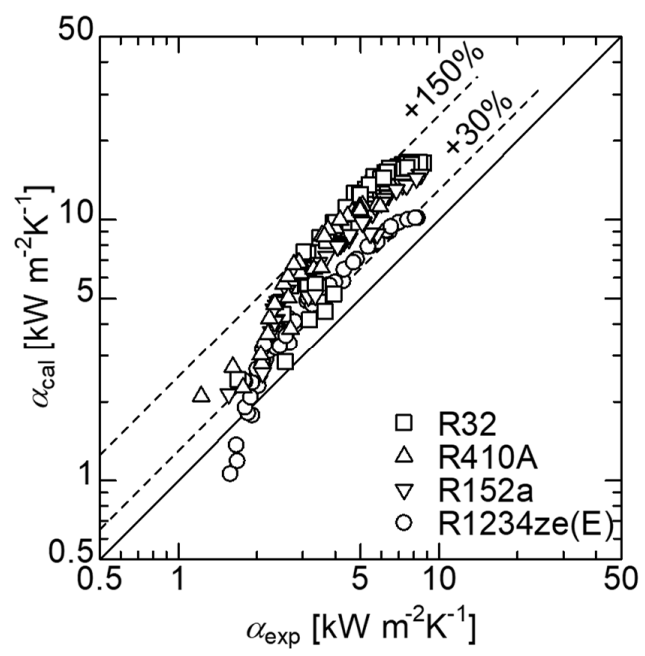

(d) Son and Lee (2009)

Figure 6. Comparison of measured and predicted heat transfer coefficient values.

\subsection{Derivation of the General Correlation for Condensation Heat Transfer in Small-Diameter Smooth Tube}

From Figure 6, it is found that the experimental values for the small-diameter smooth tube could not be correlated with sufficiently high accuracy, and could not be easily predicted by using the existing correlation. Therefore, we tried to derive an empirical correlation to predict the heat transfer coefficients, for many types of refrigerants, based on the Haraguchi et al. [2] correlation. In their correlation, Haraguchi et al. defined the $\mathrm{Nu}$ number as

$$
N u=\left(N{u_{\mathrm{F}}}^{\mathrm{a}}+N{u_{\mathrm{B}}}^{\mathrm{a}}\right)^{\frac{1}{\mathrm{a}}},
$$

where $N u_{\mathrm{F}}$ is the forced convection condensation Nusselt number, and $N u_{\mathrm{B}}$ is the free convection condensation Nusselt number. Solliman's modified Froude number $F r_{\mathrm{so}}$ was used to distinguish the wavy flow and annular flow pattern in the small-diameter smooth tube. Dobson and Chato [3] have reported that the flow is annular when $F r_{\text {so }}>20$, and wavy when $F r_{\text {so }}<20$, based on their experimental results for a small-diameter smooth tube. The Solliman's modified Froude number $F r_{\mathrm{so}}$ is found by

$$
F r_{\mathrm{so}}=0.025 R e_{\mathrm{L}}^{1.59}\left\{\left(1+1.09 \chi_{\mathrm{tt}}^{0.039}\right) / \chi_{\mathrm{tt}}\right\}^{1.5} / G a^{0.5}\left(R e_{\mathrm{L}} \leq 1250\right)
$$




$$
F r_{\mathrm{so}}=1.26 R e_{\mathrm{L}}^{1.04}\left\{\left(1+1.09 \chi_{\mathrm{tt}}^{0.039}\right) / \chi_{\mathrm{tt}}\right\}^{1.5} / G a^{0.5}\left(R e_{\mathrm{L}}>1250\right),
$$

where $R e_{\mathrm{L}}$ is the liquid Reynolds number of the refrigerant, and is defined as follows:

$$
\operatorname{Re}_{\mathrm{L}}=\left\{G(1-x) d_{\mathrm{i}}\right\} / \mu_{\mathrm{L}}
$$

where it conducts the optimization of the free convection condensation Nusselt number $N u_{\mathrm{B}}$, which is wavy when $F r_{\text {so }}<20$, as follows:

$$
N u_{\mathrm{B}}=0.297 B o^{0.11} H(\xi)\left(\operatorname{GaPr}_{\mathrm{L}} / P h_{\mathrm{L}}\right)^{0.25}
$$

where $H(\xi)$ and a void fraction $\xi$ are found by Equations (20) and (8).

$$
H(\xi)=\xi+\left\{10(1-\xi)^{0.1}-10+1.7 \times 10^{-4} \operatorname{Re}_{\mathrm{L}}\right\} \sqrt{\bar{\zeta}}(1-\sqrt{\xi})
$$

$N u_{\mathrm{F}}$ is defined as

$$
N u_{\mathrm{F}}=\sqrt{0.5 f_{\mathrm{V}}} \operatorname{Re}_{\mathrm{L}} \Phi_{\mathrm{V}}\left(\rho_{\mathrm{L}} / \rho_{\mathrm{V}}\right)^{0.5}\{x /(1-x)\}\left(P r_{\mathrm{L}} / T_{\mathrm{i}}^{*}\right),
$$

where $\Phi_{\mathrm{V}}$ and $f_{\mathrm{V}}$ are the friction factor and the two-phase pressure drop multiplier from Equations (11) and (13), respectively. $\left(\mathrm{Pr} / \mathrm{T}_{\mathrm{i}}^{*}\right)$ is obtained from the following equation, by using the Nusselt number $\mathrm{Nu}$ from Equation (23).

$$
\begin{gathered}
\left(P r_{\mathrm{L}} / T_{\mathrm{i}}^{*}\right)=\frac{\left(N u^{\mathrm{a}}-N u_{\mathrm{B}}^{\mathrm{a}}\right)^{\frac{1}{\mathrm{a}}}}{\sqrt{0.5 f_{\mathrm{V}}} \operatorname{Re}_{\mathrm{L}} \Phi_{\mathrm{V}}\left(\rho_{\mathrm{L}} / \rho_{\mathrm{V}}\right)^{0.5}\{x /(1-x)\}} \\
N u=\alpha d_{\mathrm{i}} / \lambda_{\mathrm{L}}
\end{gathered}
$$

where $\lambda_{\mathrm{L}}$ is the thermal conductivity of the refrigerant.

Figure 7a shows the relationship between $\left(\operatorname{Pr} / T_{\mathrm{i}}^{*}\right)$ and $R e_{\mathrm{L}}$ at the annular flow area $\left(F r_{\mathrm{so}}>20\right)$. The following correlations were finally obtained within $\pm 30 \%$, then, the minimal error between the experimental and predicted values was lowest by $a=5$.

$$
\left(P r_{\mathrm{L}} / T_{\mathrm{i}}^{*}\right)=0.24 R e_{\mathrm{L}}^{-0.13}\left(F r_{\mathrm{so}}>20\right)
$$

The new correlation of forced convection Nusselt number $N u_{\mathrm{F}}$ for the annular flow area $\left(F r_{\mathrm{so}}>20\right)$ was obtained from Equations (21) and (24), as follows:

$$
N u_{\mathrm{F}}=0.17 \sqrt{f_{\mathrm{V}}}\left(\Phi_{\mathrm{V}} / \mathrm{tt}\right)\left(\mu_{\mathrm{L}} / \mu_{\mathrm{V}}\right)^{0.1}\{x /(1-x)\}^{0.1} \operatorname{Re}_{\mathrm{L}}{ }^{0.87} .
$$

The correlation between the new equations and the measured data for a small-diameter smooth tube was shown in Figure $7 \mathrm{~b}$. From this, it is found that the new general correlation agrees well with the measured data of R32, R410A, and R152a, within approximately $\pm 30 \%$.

The comparison of results for R1234ze(E) for the small-diameter smooth tube was shown in Figure 8a. The predicted trend agrees with the measured values of R1234ze(E); however, the predicted value underestimates the experimental values by approximately $-30 \%$, particularly in the low wetness range. This is caused by the difference between the thermodynamic and transport properties of R1234ze(E), which is one of the low-pressure refrigerants, with the other refrigerants, which have an effect on condensation heat transfer. Figure $8 \mathrm{~b}$ shows the comparison between the experimental data of Longo et al. [16] and the present correlation for R404A and R290. The figure shows that the trends in the entire wetness region generally agree within $\pm 30 \%$; it was found that the present correlation can be applied to R404A and R290 refrigerants. 


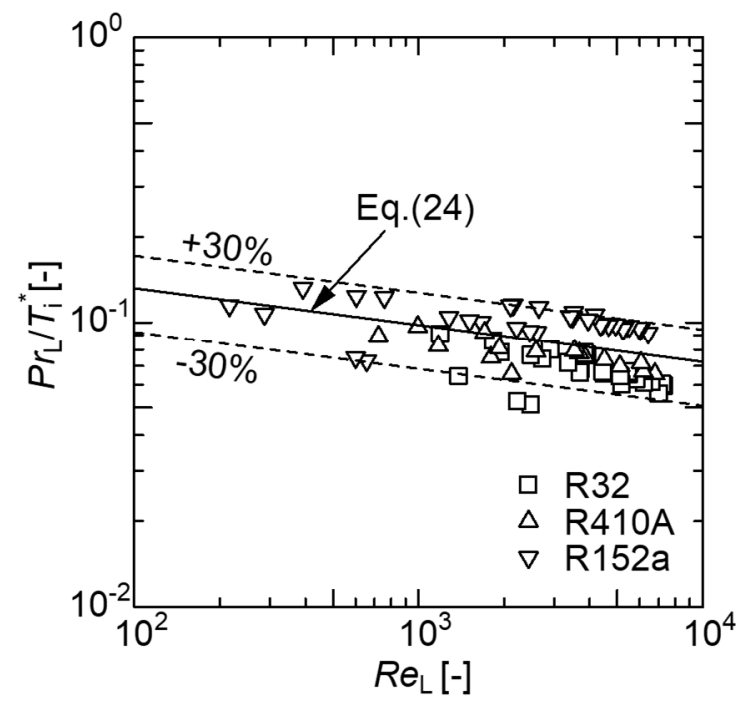

(a)

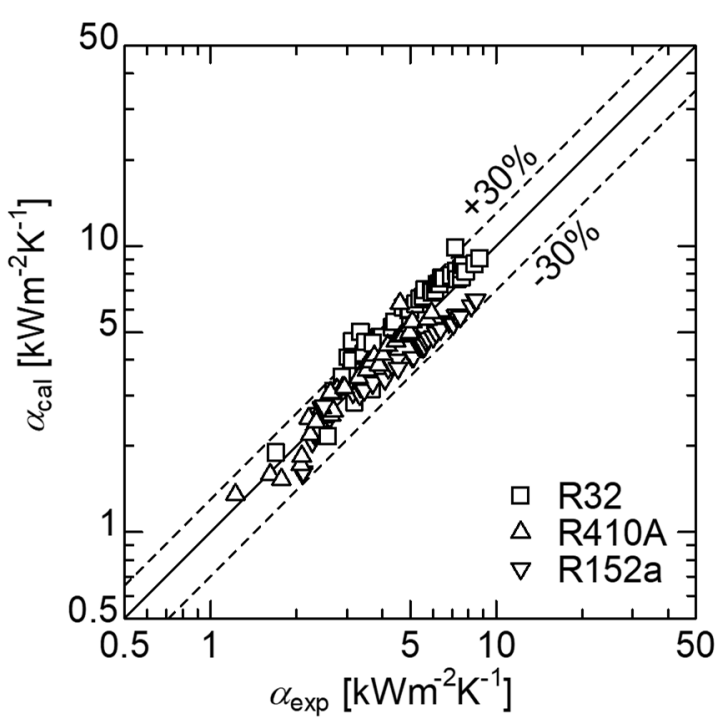

(b)

Figure 7. (a) Relationship between relative temperature difference and liquid Reynolds number in R32, 410A. (b) Heat transfer coefficient correlation between that predicted by the present correlation, and the measured values of R32, R410A, and R152a.

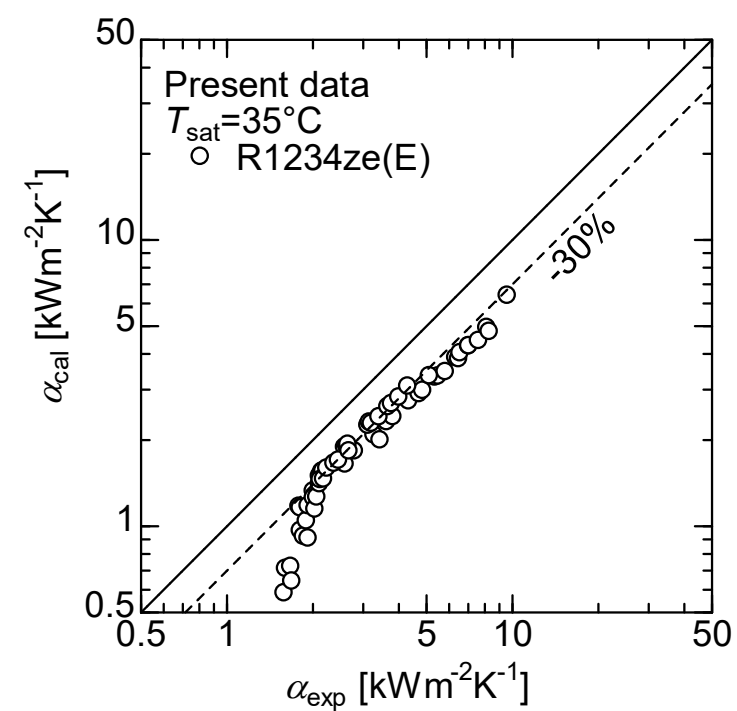

(a)

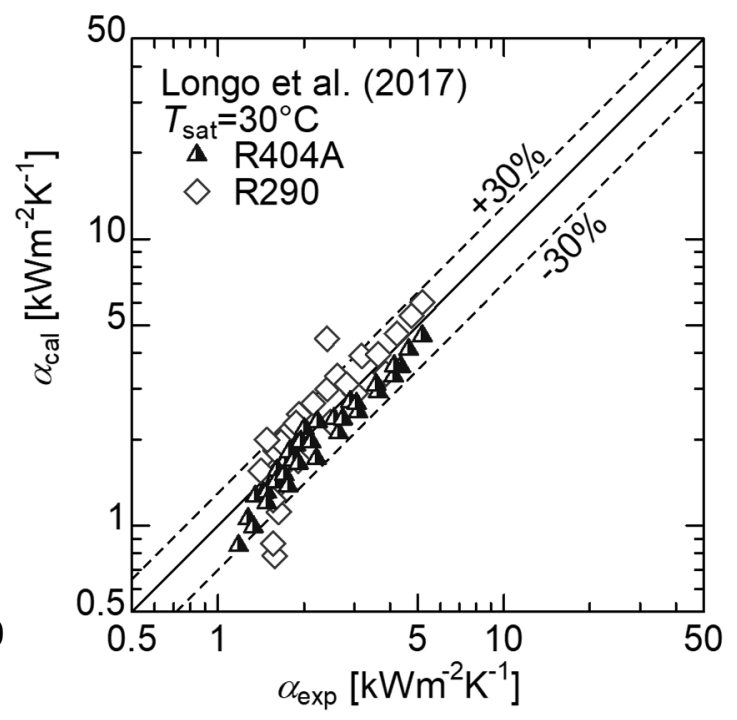

(b)

Figure 8. (a) Comparison of the heat transfer coefficient between that predicted by the present correlation, and the measured values of R1234ze(E). (b) Comparison of heat transfer coefficient between that predicted by present correlation, and data from Longo at al. for R404A and R290.

\section{Conclusions}

The experiments to obtain data on the condensation heat transfer coefficient and frictional pressure drop, by using a 4 mm outside diameter smooth tube and R32, R152a, R410A, and R1234ze(E) as test refrigerants, were conducted in this paper. Additionally, the new general correlation of the condensation heat transfer, for broad application on small-diameter smooth tube and several kinds of refrigerants, was proposed. The results are as follows:

(1) The frictional pressure drop of R1234ze(E) can be correlated within $\pm 30 \%$ by our previous general correlation of frictional pressure drop for the small-diameter smooth tube. 
(2) For small-diameter smooth tubes, the condensation heat transfer coefficient can be predicted within $\pm 30 \%$ by the correlation of Cavallini et al., which has the highest accuracy among the previously proposed correlations.

(3) A new general correlation, by a simple and convenient method for estimating the condensation heat transfer for small-diameter smooth tubes and several kinds of refrigerants, was proposed. The predicted trend agrees with the measured values of R1234ze(E); however, the predicted value underestimates the experimental values by approximately $-30 \%$, particularly in the low wetness region.

Author Contributions: N.I. conducted this project, wrote the paper and instructed the experimental analysis. M.H. and J.I. designed, built and operated the experimental setup and performed the experimental analysis. D.J. operated the experimental setup and corrected the calculation of experimental analysis and paper formatting.

Funding: This study was supported by the Research \& Development Section, Technical Department, Kobelco \& Material Copper Tube Ltd., and assisted during the experiment by Kouhei Fujima (Graduate School student).

Acknowledgments: We would like to express our gratitude for the support provided.

Conflicts of Interest: The authors declare no conflicts of interest.

\section{Nomenclature}

A

Bo

$c_{P}$

$d$

$f$

$\mathrm{Fr}_{\mathrm{SO}}$

G

g

Ga

$h_{\text {fg }}$

L

$\mathrm{m}$

$\mathrm{Nu}$

$N u_{\text {B }}$

$N u_{\mathrm{F}}$

$P$

$P h$

Pr

$Q$

$R e_{\mathrm{L}}$

$R e_{\mathrm{V}}$

$T$

$T_{\mathrm{i}}^{*}$

$x$

\section{Greek Symbols}

$\alpha$

$\Delta P$

$\Delta P_{\mathrm{F}}$

$\Delta P_{\mathrm{M}}$

$\lambda$

$\mu$

$\xi$

$\rho$ heat transfer area $\left(\mathrm{m}^{2}\right)$

Bond number $=\left(\rho_{\mathrm{L}}-\rho_{\mathrm{V}}\right) g d_{\mathrm{i}} / \sigma$

isobaric specific heat $\left(\mathrm{J} \mathrm{kg}^{-1} \mathrm{~K}^{-1}\right)$

tube diameter $(\mathrm{m})$

friction factor

Solliman's modified Froude number

refrigerant mass velocity $\left(\mathrm{kg} \mathrm{m}^{-2} \mathrm{~s}^{-1}\right)$

gravitational acceleration $\left(\mathrm{m} \mathrm{s}^{-2}\right)$

Galileo number $=g d_{\mathrm{i}}^{3} \rho_{\mathrm{L}}^{2} / \mu_{\mathrm{L}}^{2}$

latent heat of condensation $\left(\mathrm{J} \mathrm{kg}^{-1}\right)$

heat transfer length $(\mathrm{m})$

mass flow rate $\left(\mathrm{kg} \mathrm{s}^{-1}\right)$

Nusselt number $=\alpha d_{\mathrm{i}} / \lambda_{\mathrm{L}}$

free convection Nusselt number

forced convection Nusselt number

pressure $(\mathrm{Pa})$

phase change number $=c_{\mathrm{P}}\left(T_{\mathrm{r}}-T_{\mathrm{wi}}\right) / h_{f g}$

Prandtl number $=\left(c_{\mathrm{P}} \mu\right) / \lambda$

heat transfer rate of each subsection (W)

liquid Reynolds number $=G(1-x) d_{\mathrm{i}} / \mu_{\mathrm{L}}$

vapor Reynolds number $=G x d_{\mathrm{i}} / \mu_{\mathrm{V}}$

temperature (K)

dimensionless temperature difference

vapor quality

heat transfer coefficient $\left(\mathrm{W} \mathrm{m}^{-2} \mathrm{~K}^{-1}\right)$

total pressure drop $(\mathrm{Pa})$

frictional pressure drop $(\mathrm{Pa})$

acceleration pressure drop $(\mathrm{Pa})$

thermal conductivity $\left(\mathrm{W} \mathrm{m}^{-1} \mathrm{~K}^{-1}\right)$

viscosity (Pa s)

void fraction

density $\left(\mathrm{kg} \mathrm{m}^{-3}\right)$ 


$\begin{array}{ll}\Phi & \text { two-phase pressure drop multiplier } \\ X_{\mathrm{tt}} & \text { Lockhart-Martinelli parameter } \\ \text { Subscripts } & \\ \text { cal } & \text { calculated value } \\ \text { c } & \text { heat-source water } \\ \text { exp } & \text { experiment } \\ \text { i } & \text { inside } \\ \text { L } & \text { liquid } \\ \text { n } & \text { subsection number } \\ \text { o } & \text { outside } \\ \text { pre } & \text { pre-condenser } \\ \text { r } & \text { refrigerant } \\ \text { sat } & \text { saturated } \\ \text { so } & \text { Soliman } \\ \text { V } & \text { vapor } \\ \text { W } & \text { wall }\end{array}$

\section{References}

1. Haraguchi, H.; Koyama, S.; Fujii, T. Condensation of Refrigerants HCFC22, HFC134a and HCFC123 in a Horizontal Smooth Tube: 1st Report, Proposals of Empirical Expressions for Local Pressure Drop. J. Jpn. Soc. Mech. Eng. 1994, 60, 239-244. (In Japanese)

2. Haraguchi, H.; Koyama, S.; Fujii, T. Condensation of Refrigerants HCFC22, HFC134a and HCFC123 in a Horizontal Smooth tube: 2nd report, Proposals of Empirical Expressions for Local Heat Transfer Coefficient. J. Jpn. Soc. Mech. Eng. 1994, 60, 245-252. (In Japanese)

3. Dobson, M.; Chato, J. Condensation in Smooth Horizontal Tubes. J. Heat Transf. 1998, 120, 193-213. [CrossRef]

4. Cavallini, A.; Del Col, D.; Doretti, L.; Matkovic, M.; Rossetto, L.; Zilio, C. Condensation in Horizontal Smooth Tubes: A New Heat Transfer Model for heat Exchanger Design. Heat Transf. Eng. 2006, 27-28, 31-38. [CrossRef]

5. Hossain, M.A.; Onaka, Y.; Miyara, A. Experimental Study on Condensation Heat Transfer and Pressure drop in Horizontal Smooth Tube for R1234ze(E), R32 and R410A. Int. J. Refrig. 2012, 35, 927-938. [CrossRef]

6. Han, B.; Liu, F.; Cai, D.; Tian, Q.; He, G. Experimental Study on Condensation Heat Transfer of R32/R290 Mixture in Horizontal Tubes. Appl. Therm. Eng. 2015. [CrossRef]

7. Son, C.; Lee, H. Condensation Heat Transfer Characteristics of R-22, R-134a and R-410A in Small Diameter Tubes. Heat Mass Transf. 2009, 45, 1153-1166. [CrossRef]

8. Matsumoto, T.; Arata, Y.; Miyata, K.; Hamamoto, Y.; Mori, H. Experiment on Condensation Heat Transfer of HFC134a in a Horizontal Single Rectangular Mini-channel. In Proceedings of the 9th Asian Conference on Refrigeration and Air-conditioning 2018, Sapporo, Japan, 10-13 June 2018.

9. Longo, G.A.; Mancin, S.; Righetti, G.; Zilio, C. R134a and Its Low GWP Substitutes R1234yf and R1234ze(E) Condensation inside a $4 \mathrm{~mm}$ Horizontal Smooth Tube. In Proceedings of the 17th International Refrigeration and Air Conditioning Conference at Purdue 2018, West Lafayette, IN, USA, 9-12 July 2018.

10. Longo, G.A.; Mancin, S.; Righetti, G.; Zilio, C. R410A and Its Low GWP Substitutes R32 Condensation inside a $4 \mathrm{~mm}$ Horizontal Smooth Tube. In Proceedings of the 16th International Heat Transfer Conference 2018, Beijing, China, 10-15 August 2018.

11. Inoue, N.; Ichinose, J. Single-phase Heat Transfer and Pressure Drop inside Internally Helical-grooved Horizontal Small-diameter Tubes. Int. J. Air-Cond. Refrig. 2012, 20. [CrossRef]

12. Ichinose, J.; Inoue, N. The Condensation Heat Transfer and Pressure Drop of R410A and R32 inside Horizontal Small-diameter Tubes-2nd Report: Empirical Correlation for Condensation Heat Transfer and Pressure Drop. Trans. JSRAE 2011, 28, 479-490. (In Japanese)

13. Hirose, M.; Ichinose, J.; Inoue, N. Development of the general correlation for condensation heat transfer and pressure drop inside horizontal $4 \mathrm{~mm}$ small-diameter smooth and microfin tubes. Int. J. Refrig. 2018, 90, 238-248. [CrossRef] 
14. Lemmon, E.W.; Huber, M.L.; McLinden, M.O. NIST Standard Reference Database 23, Reference Fluid Thermodynamic and Transport Properties REFPROP Ver. 9.1; National Institute of Standards and Technology: Gaithersburg, MD, USA, 2013.

15. Smith, S.L. Void Fractions in Two-Phase Flow: A Correlation Based upon an Equal Velocity Head Model. Proc. Inst. Mech. Eng. 1969, 184, 647-664. [CrossRef]

16. Longo, G.A.; Mancin, S.; Righetti, G.; Zilio, C. Saturated vapour condensation of HFC404A inside a $4 \mathrm{~mm}$ ID horizontal smooth tube: Comparison with the long-term low GWP substitutes HC290 (Propane) and HC1270 (Propylene). Int. J. Heat Mass Transf. 2017, 108, 2088-2099. [CrossRef]

2018 by the authors. Licensee MDPI, Basel, Switzerland. This article is an open access article distributed under the terms and conditions of the Creative Commons Attribution (CC BY) license (http://creativecommons.org/licenses/by/4.0/). 